\title{
Reason and rhetoric in climate communication
}

(Environmental Politics, 2015, 24(1), p.1-16)

\author{
John S. Dryzek * and Alex Y. Lo $\ddagger$ \\ * Centre for Deliberative Democracy and Global Governance, University of Canberra, \\ Australia. \\ ‡ Griffith School of Environment, Griffith University, Gold Coast, Australia. \\ Email: alex.lo@griffith.edu.au (corresponding author)
}

\begin{abstract}
Rhetoric can facilitate movement beyond impasse on whether and how to confront climate change, enabling more effective public reasoning. Our evidence comes from a small deliberative group that contained climate change deniers. We show how in this setting bridging rhetoric (capable of reaching those who do not share the speaker's perspective) managed to bring deniers and others into accepting that particular greenhouse gas mitigation measures were in the range of acceptable policy choices even as deniers continued to dispute the existence of anthropogenic climate change. What we observed drives home the need for rhetorical bridges in broader public debates on climate change.
\end{abstract}

\section{Keywords}

Rhetoric, climate change, climate sceptics, deliberative democracy 


\section{Introduction}

The public debate on climate change in developed Anglo-American countries (notably the United States, Canada, Australia, and to a lesser extent the United Kingdom) has in recent years featured partisan acrimony fuelled by the rising prominence of scepticism and denial of the existence of anthropogenic climate change (Dunlap and McCright 2008, Hulme 2009, Whitmarsh 2011). Many climate scientists and environmental activists continue to believe the best response is to ramp up the evidence-based arguments. For example, in response to a questioner at his plenary speech at the 2012 Planet Under Pressure Conference in London, Anthony Giddens (2012) called for renewed 'assault' on the arguments of climate change sceptics. However it is quite likely that this conventional approach, based on implicit assumptions about rational publics capable of assimilating and weighing the evidence, and acting accordingly, has run its course. As Moser and Dilling (2011) demonstrate, there are three things that we now know make little further difference when it comes to communicating climate change to the public: providing more and better information does not have an effect; inculcating fear of the effects of climate change does not lead people to support stronger mitigation and adaptation policies; and asserting the authority of science and scientists does not lead to public acceptance of the scientific consensus on the severity of climate change.

We know, then, what does not work. But we have less idea about what does work. Here we will identify what we believe to be one piece of the puzzle: more effective rhetoric. Rhetoric involves persuasion in all its forms (including rational argument). A catalogue of rhetorical devices would stretch to over a hundred, but here we will stress just two that proved able to facilitate bridging across different worldviews in one 
particular case. The first is the use of analogy, or reasoning from parallel case, whose centrality in rhetoric was recognized long ago by Aristotle (Higgins 2008, p. 6). Analogy compares two things similar in some familiar aspects in order to induce acceptance of an unfamiliar aspect. The second is framing, which induces the listener to see problems and their causes and remedies in a particular kind of way, rendering some aspects of the world salient, others irrelevant (on the centrality of framing to rhetoric, see Kuypers 2009). Other rhetorical devices might play roles in different settings involving communication on climate change.

We do not claim that better deployment of bridging rhetoric is sufficient to move public debate beyond partisan impasse, but we do believe that it is one necessary condition for this movement to happen. A contrast between reason and rhetoric began with Plato (and philosophers reinforce the contrast to this day). Here we will suggest that though rhetoric has aspects that are not reducible to reason, those aspects may actually facilitate effective public reasoning. Appreciation of the constructive roles that rhetoric can play in politics also dates back a long time - to Aristotle. This paper is Aristotelian, not Platonic. Our argument is made not through reference to rhetoric in the larger public sphere, but rather to one place where we might think rhetoric would be least likely to find a home: a designed deliberative citizens' forum on climate policy. In contrast to Hobson and Niemeyer (2012), who found that deliberation in a citizens' forum only induced sceptics to harden their positions, we found that sceptics could be induced into productive dialogue. Our explanation for this difference is that our forum featured some rhetorical moves absent from the Hobson and Niemeyer forum. If rhetoric can play a positive role in facilitating effective deliberation in such a setting, its positive role in the larger public 
sphere should become much easier to accept. One advantage of using a small-group study is that it enables us to trace through the effects of rhetoric in a setting largely insulated from the numerous confounding factors that exist in any debate that extends more broadly over time and space.

Climate sceptics come in many varieties (Poortinga et al. 2011, Corner et al. 2012, Washington and Cook 2011). Some are sceptics in taking nothing on trust, requiring evidence and reasons before they can be convinced of a position. Bjørn Lomborg, the self-styled 'sceptical environmentalist', revealed himself to be a sceptic in this sense in announcing that 'We have long moved on from any mainstream disagreements about the science of climate change' (Lomborg 2010, p. 1). Beyond tractable scepticism of this sort, Hobson and Niemeyer (2012) enumerate nine types of denial, ranging from insistence that climate change does not occur to uncertainty about its consequences. The psychological sources are equally numerous. Kahan et al. (2012) argue that, in the United States, belief in the reality or otherwise of climate change has become a marker for cultural identities (see also McCright and Dunlap 2011). Familiar psychological mechanisms such as unwillingness to confront uncomfortable truths also operate (Norgaard 2011). Our concern here is with the intractable kind of denial, rooted in worldviews that cannot allow the existence of human influence on climate change. Though beyond the reach of reason, such positions are not necessarily beyond the reach of rhetoric, and can actually be brought into an effective deliberative system for tackling climate-related issues. We emphasize 'can' - we do not claim that the effect we identify is universal in its reach, simply that its potential cannot be ignored when it comes to communicating climate change. 
Our evidence comes from a citizens' forum on climate change, conducted in Australia, that included climate change deniers. Our argument hinges on the idea that though such individuals cannot be brought into accepting the content of climate science, they can come to accept the legitimacy of measures that require people to contribute financially to policies for greenhouse gas reduction and even consent to their adoption. So we are going to suggest that it is possible to move forward in discussions about policy while dissensus remains at the simple epistemic level, however illogical this might seem at first sight. Rhetoric can move people when logic does not - and this is our main message here. Climate change deniers can, then, end up consenting to mitigation policies - in the case we have studied, a levy to finance mitigation of greenhouse gas emissions. This does not mean such action necessarily becomes their first preference. But continuing dissensus at the level of individual preferences does not preclude deniers being able to live with the action. So let us now turn to our case in order to demonstrate these effects.

\section{A citizens' deliberative forum on climate change}

A deliberative forum on climate change policy was held on 31 July 2010 in Canberra, Australia. Twenty-four ordinary citizens were recruited from the Canberra region. Fifteen males and nine females, most were middle-aged and educated, working professionals. While the workshop participants were not representative of the regional population in any statistical sense, for present purposes that does not matter. More important was the presence of climate change deniers within the forum. The small number of individuals is immaterial because we do not claim that any causal mechanism we locate is generalizable to some larger population. More important is the nature of the mechanism and how it can 
inspire the search for something that would produce similar results in the larger public sphere.

During the workshop, participants were involved in a series of group discussions on carbon pricing and clean energy financing issues after scientific presentations of information relating to the topics under discussion. The objectives of the workshop were to evaluate current government policy towards climate change, consider the future of the Australian emissions mitigation policy, and assess potential economic implications. Four specialists were involved as invited presenters to share information and knowledge related to the science of climate change, the economic and policy implications of climate change, international climate politics, and the economics of emission trading and carbon taxation.

Group discussions were interspersed with the presentations. The first session focused on 'concern about climate change', where the participants thought about defining the problem at hand and explored issues such as Australia's responsibility in greenhouse gas reduction. The theme of the second session was 'carbon pricing'. The discussion explored the merits of four possible carbon pricing arrangements; emissions trading, carbon tax, voluntary carbon offsetting and doing nothing. In the third session, participants considered a range of issues under the theme of 'financing low-emission energy technologies'. This session addressed willingness to contribute financially to research and development of low-emission technologies. Participants formed three groups to discuss each topic, with a facilitator for each group.

\section{What changed in the forum}


The participants' tasks included ordinal ranking of the abovementioned four carbon pricing options (from most preferred to least preferred). At the outset, a carbon tax was most favoured, receiving 12 primary votes, compared to nine for emissions trading. Three individuals preferred no official pricing on carbon or unofficial pricing through voluntary offset markets. After deliberation, the number of participants with a first preference for a carbon tax increased from 12 to 16.

The underlying dispositions of the participants were also surveyed using Q methodology (for details see Lo 2013). The majority of participants believed that climate change is human induced and accepted the moral responsibility for an active national response. On issues relating to policy principles, this majority was split into two groups: some stressed efficiency and leaned towards market-based emissions reduction policies, whereas others preferred state-led regulatory programs. A minority position was characterised by denial of the existence of human-induced climate change and opposition to actions designed to mitigate emissions. This minority position was strongly supported by two participants, whom we label Mike and Nancy.

The relative strength of the three positions did not change during deliberation. This assessment was based on two observations (Lo 2013). The first is about the numbers of participants subscribing to them, in terms of significant factor loading of each participant on each position. None of these positions, including the minority position, had fewer subscribers after deliberation. The second is the strength of subscription. The average factor loading of each position did not decline, suggesting that none of them was weakened as a result of deliberation. This does not mean that participants did not modify their opinions at all; in fact, most had changed their mind to different extents. The key is 
that movements between positions were reciprocal, that is the two climate deniers and some other participants became more sympathetic toward each other's positions, without significantly moving away from their original positions. Deliberation facilitated mutual understanding without displacing any one of these positions. The views of the two climate deniers warrant further exploration.

Both before and after deliberation Mike and Nancy did not accept the science of climate change. However before deliberation they categorically rejected proposals for emissions trading and carbon taxation. They saw no need for pricing carbon, and were not willing to pay anything for emissions mitigation. At the end of the process their scepticism and rejection of the science remained, but they were both willing to regard compulsory financial contributions to measures that would reduce greenhouse gas emissions as legitimate policy options. We shall try to explain this apparent paradox and what it suggests about strategies for communicating climate change.

These observations suggested an emerging agreement on what could be done, coupled with persisting underlying differences in values and beliefs. What happened during the one-day workshop that raised the capacity to cooperate while preserving subjective variations? We will examine the transcripts of the formal group deliberations to answer this question. Our explanation turns on rhetorical moves made in the group deliberations that eventually facilitated pragmatic consent about what to do.

\section{What happened during deliberation}

Initial expressions of deep difference 
Discussions began with palpable tension. Some participants expressed their concerns about the influence of climate scepticism in Australia. One of them, James, started his conversation with a cynical tone: 'No climate sceptics here?', and Ross responded 'Well there are some, there are people who are sceptical about it. They don't believe that it's happening at all'. Those who interacted with sceptical individuals in the general community tended to be hostile towards sceptical viewpoints. For instance, when describing a local campaign promoting energy efficiency, Dave claimed they were 'fighting climate change deniers' and Kevin echoed this sentiment immediately by referring to his own experience.

Mike identified himself as a 'denier': 'This has become a polarised argument amongst two distinct camps; those who believe that recordable global warming is not a result of human activity and those who believe that the emission of industrial carbon gases is directly the cause of irregular weather patterns......My views are more directly associated with the first camp.' In terms of the categories developed by Hobson and Niemeyer (2012, p. 402), Mike is therefore an 'emphatic causal sceptic'. The sceptical individuals offered two main arguments. The first argument was based on incomplete evidence to substantiate anthropogenic climate change claims. Perceived uncertainties and limits of current knowledge backed suspicion of the scientific propositions concerning the significance of the problem. Doubts were expressed that the current level of greenhouse gas concentrations has reached a tipping point: 'So we have less of a carbon dioxide, amongst other gases, absorption, so as you industrialise and farm more land there's less ground absorption. So everything you say Kevin is right, but it's grouped up now to what extent. What percentage?'(Mike). The second argument was that 
Australia has made a minimal contribution to global climate change: 'we are not the biggest polluters on Earth anyway, are we?' (Nancy). (Actually on a per capita basis Australia is one of the biggest polluters, exceeded only by a few oil-exporting countries.)

Conflict began to surface as participants felt more comfortable and became more expressive during the workshop proceedings. When Kevin tried to exclude the options of merely voluntary offsetting and carbon pricing from further consideration, Mike indicated his reluctance by saying 'Yes, I give the "no carbon pricing” at this stage' and was seconded by Nancy: 'I'm going with the last one too'. Kate was also leaning toward this option on the grounds that, as global initiatives were yet to be put in place, so there was no point in Australia acting on its own. Division unfolded as concerns about carbon pricing were further discussed. Explicit disagreements between the two 'camps', notably between Mike and Kevin, indicated heightened conflict. Putting a price on carbon was deemed unnecessary by the sceptic Mike.

\section{Emerging points of agreement}

Disagreements appeared to diminish when participants turned their attention to government and politicians. We highlight the rhetorical device of reframing toward a discourse about trust in government (and other institutions) because it eventually proved the key to a resolution that could encompass not just proponents of different sorts of mitigation policies, but also climate change deniers. Several participants expressed a cynical attitude toward the capability of government: 'they can't even do pink batts and you're wanting them to look after an emissions trading scheme?' said Philip. ('Pink batts' refers to a scandal-plagued government scheme to insulate houses.) When prompted to 
evaluate the government's contributions to addressing climate change, Ian responded 'It hasn't done anything' and Brian echoed 'You're joking'. The discontent was extended to politicians in general. Failure properly to respond to climate change issues and develop mitigation plans was attributed to 'playing politics'. Some participants contended that politicians turned a deaf ear to the evidence of climate change. The participants were united in complaint that partisan politics rather than addressing the state of the global environment was the main game. Common ground became more evident as cynical comments were shared.

Having discerned shared concerns, individuals previously divided on the merits of a carbon tax versus an emissions trading scheme were able jointly to articulate criteria for a carbon pricing policy. These criteria were clear emissions reduction targets, dedicated use of the funds raised, accountable allocation systems, and guaranteed reduction in emissions. Advocates of ETS were not in favour of carbon taxation because 'It doesn't give a guarantee of the emissions reduction' (Elaine), whereas ETS is 'an almost guaranteed way of reducing a very specific amount of pollution' (John). Carbon tax supporters wanted similar guarantees. Dedicated use of the revenue raised proved to be a key criterion reiterated within all groups, as James explained: 'I think it's a simple system and if we had a carbon tax and if we made it a dedicated carbon tax, dedicated meaning all the taxes collected from that goes to a particular cause or purpose'.

Sceptical individuals proved not to oppose spending money on the development of low-emission technologies. Operating in terms of the emerging frame of trust (and distrust) in government and other institutions, their endorsement was predicated upon a guarantee of strict dedication: 'can we be sure that all of those levies do go towards this 
research and development and assistance in construction of wind farms or whatever it might be. Not disappear back into consolidated revenue', said the sceptic Mike.

Central to all sides were the questions; 'where is the money going?' and 'what is going to be achieved with it?’ The common keywords across all three groups (sceptics, ETS-, and tax-supporters) were 'guarantee', 'dedication', and 'accountability', and this common ground proved key to moving the discussion beyond impasse concerning what to do.

Questions of trust were more frequently invoked as time went on. In many instances, participants appeared hesitant to endorse a particular policy option because of their lack of trust in businesses and in bureaucrats who would be responsible for administering it. They suggested that carbon pricing could provide electricity companies with a legitimate reason to raise prices and doubted that the companies would properly allocate the money to reduce their emissions. Emissions trading was thought by some participants to be too vulnerable to corruption. As Liana explained, with agreement from Dave, 'This trading scheme is too vulnerable to shonky dealing, shonky offsets, and weird sorts of trading loopholes'. Although carbon tax supporters tended to be suspicious of markets, some were also suspicious of government: 'I don't trust the government - I don't want it to go into a general fund and they feel like they can spend it on carbon capture, which I don't believe in' (Dave).

Lack of trust also contributed to the unpopularity of voluntary offsetting:

John: I've sort of generally always on principle, refused to buy them [carbon offsets]. I don't know the system they're going to. They always do 
research into what it's going to but I really don't know where that money is going to.

Brian: It's a lack of trust.

John: Yeah, I just don't trust the system.

Crucially, Mike, the climate sceptic, had little disagreement on this point: 'No. You can't trust business to actually take the place of government. There are certain things that government has a total responsibility for and one of them is the mechanism - a control of price'.

Shared concerns derived from the trust frame did, then, contribute to understanding across the different participants. As Dave observed: 'I think of all these things we're discussing today, the matter of trust seems really important. We all do not really seem to trust governments. Some of us don't trust the markets'. Those who trusted government more than the market included the climate sceptic Mike and, as we will see, this enabled him to accept a particular sort of mitigation policy, though one further crucial rhetorical move proved necessary, to which we now turn.

\section{The rhetorical analogy of 'Medicare for the climate'}

Opinions remained split on what the government should do and why. Nevertheless there was no dispute that the institutions needed must be reliable and trustworthy. A creative analogy from one of the participants that involved a trusted part of Australian government proved capable of convincing the participants eventually to accept - but not necessarily fully support - the idea of a dedicated tax for curbing emissions understood as resembling the Australian Medicare levy. The Medicare levy is a popular tax that funds Australia's 
public universal health care system. Introduced in 1975 as 'Medibank' and renamed in 1984, Medicare provides affordable treatment by doctors and in public hospitals for all resident citizens and permanent residents of Australia. The program is now nominally (but not completely) funded by a levy set at 1.5\% of income (with an extra $1 \%$ for higher income earners).

The idea of a Medicare levy received attention and had greater impacts on the most deeply divided deliberating group, whose members ought therefore to be those least likely to reach a simple consensus, compared to the other two groups. This group included a vocal ETS supporter (Kevin), the two clear climate sceptics (Mike and Nancy), and a more hesitant sceptic (Kate). The mix of participants was a unique feature of this group that allows us to show how the Medicare idea could bridge deep differences. The idea was first proposed by Helen: 'right now today we could start a Medicare levy for the environment and have it at a really low level, start off just getting it, and we want to call it a carbon tax or an environmental levy or something and it's really low percentage wise.' The idea soon received support from her group members and they appeared confident and excited when responding.

Helen: That's why I want this environmental tax thing to start tomorrow. Start it tomorrow and the rest of it we feed into it and we grow from there.

Dave: $\quad$ Medicare for the environment.

Helen: It needs it.

Sarah: The administrators are already there. The department that governs it is already in place. 
Helen: The structures are in place, we know how to do deal with it, okay everybody will have to pay a bit more. Immediately the Government will have money that can start putting in infrastructure to help renewable, if that has to go into communication, promotion, marketing, killing Alan Jones [a populist anti-environmentalist talkback radio broadcaster], I don't know what it means, it can start spending money now, not in three years, not in six years, not in 10 years.

The participants were all familiar with the Medicare levy and had first-hand experience with the system. The levy was trusted and seen as dedicated to the good of the people. The idea of an administrative system designed in the same terms as the Medicare levy proved attractive to just about all the participants. As we noted at the outset, in rhetorical theory analogy works precisely because it adds a new element to a set of familiar and accepted ideas.

Most importantly, the idea of Medicare for the climate received recognition from opponents of a carbon tax, who could find sympathy for a familiar and seemingly accountable tax. Kevin, who favoured emissions trading all the way through, said:

'Well I like the Medicare. I think if you set it at one per cent or whatever and everybody pays and at the end of the year it goes in ... then they can deal with it. It's got to be able to be flexible enough to not slam the poor and not let the rich get off with not paying.' 
This is the levy that we're going to pay that would go directly for renewable energy. Like you suggested, it seems to make sense to me that Medicare possibly would be a branch of government that would handle that. Or whatever's appropriate. The carbon tax compensates the less fortunate especially, plus it encourages the businesses to cut down on their use or production of carbon.

Although the tension between carbon tax and emissions trading remained, Kevin's acceptance of the carbon tax as a legitimate policy option appeared to be driven by the analogy of 'Medicare for the climate'.

The appeal of established confidence in the Medicare system was effective in reaching the two climate sceptics. Nancy showed willingness to pay for low-emission technologies, provided that payment would be collected through a Medicare-like system: 'What is the Medicare levy used for? Is it very straightforward - we pay it and the government gets it and spends it only on Medicare purposes. Because if that's the same then one could agree with that. That they could then be equally safe, you know......Then we have a blueprint for it, you know. So that could be done and could be safe.' Her support was conditional upon the mechanism of the proposed carbon levy resembling the existing Medicare system - again reflecting the way analogy is supposed to work in rhetorical theory.

The Medicare analogy also reached the other sceptic, Mike, who as a result became less opposed to the idea of carbon pricing per se, as opposed to pricing through markets: 'The biggest thing I thought we'd have to avoid was having the costing of this fall into the hands of the market that can set an artificial price. I really do think if a cost is going to 
put on it, it's got to be established by Government, what that cost does.' As reported above, he would not accept allocating the funds raised to a party such as industry that is not accountable to the people. In the post-workshop communication, he reiterated his acceptance of a carbon levy, which he thought was 'transparent', but not a carbon tax. The acceptance stemmed from his belief that such a carbon levy could meet two criteria:

Further discussion arrived at a group consensus that agreed on this form of financing as being appropriate towards $R \& D$ funding. Two factors emerged in that there was already an established system to manage a levy as all infrastructure was in place and a means of collection existed..... It was stressed that any levy so collected from the taxable public was to be quarantined as a sole payment towards GHE [greenhouse emission] $R \& D$.

The emphasis on 'established' and 'quarantined' sufficiently reflected the two critical trust considerations articulated by the participants. The Medicare levy analogy addressed their key concerns head-on. We emphasize that though the levy became acceptable to sceptics Mike and Nancy, especially as part of a collective decision, it did not necessarily become their first preference. Thus there was no simple group consensus in the sense of universal agreement on a first preference in a preference ordering. But as Dryzek and Niemeyer (2006) point out, the main point of deliberation is to induce a 'meta-consensus' around the legitimacy of particular options, not simple consensus on a first choice. Metaconsensus can then facilitate the construction of a workable agreement on what to do. 
Following a plenary session in which several participants referred to a levy, and a tea break in which members of the three groups mingled, the levy idea was taken up to positive effect in the other two groups. We see similarities in the reasons for accepting the idea across all three groups. The discussions about it were always built upon the participants' concerns highlighted by the frame of trust in institutions.

Members of the other two groups moved into a levy-thinking mode when they discussed examples of a trusted or distrusted system. Without anyone formally proposing a 'Medicare for the climate', some participants referred to it as a possible policy response. For instance, when asked to what extent a return of recession would reduce willingness to pay, a participant responded: 'We all had to pay the Medicare levy last year didn't we? Whether there was a financial crisis or not, everybody still had to fork out for the Medicare levy'. Some participants even saw it as alternative to a sales tax to finance emissions reduction: 'Or in the style of a Medicare levy'. As in the first group, some raised an accountability issue about the proposed levy - 'But to take up the accountability - I'd like to know what that's going to be spent on' - but were reassured by the fact that the existing Medicare levy is dedicated to a particular purpose and so would be for the proposed levy: 'All the money is dedicated to establishing a low carbon economy'. The proposal was seen to be able to address the certainty concerns discussed above. The participants did not necessarily trust government in general; the appeal of the Medicare levy is that it does not give government discretionary power over how to spend the revenue.

Reliability was also a key consideration. A counterexample was provided by Alan, who rejected the idea of 'a levy on electricity bills' because of the potential commercial 
interest involved: 'I've got a bit of a concern about all these special levies. A good example is air travel. There's all these uplifts - you don't know what they are and where they're going. We should trust the government - they raise revenue and then it's their job to appropriate it sensibly.' He would probably take issue with the proponents of the carbon levy. However, his hostility was to the idea that the levy might be administered by private companies, such as airlines. He trusted the government more. Other group members responded in a similar way that the proposed levy would not be attractive if it were administered by private companies. So acceptability of the levy concept turned on the trust frame that the participants had already established.

Being income-based, the proposed levy would primarily apply to individuals, rather than to firms. The levy would not exactly involve pricing carbon directly - though when Helen first introduced 'Medicare for the environment' into the discussion, she explicitly linked it to the carbon tax. The participants in proposing a modified 'tax' did not explicitly address the tension between the levy idea and the specific qualities of the carbon tax and emissions trading. A rhetorical reading of the effect of 'Medicare for the climate' is that the idea established a policy framework and principles on which the subsequent endorsement of a taxation programme to be operated by government agencies and regulate prices could be based. The proposal does involve recognition that there is a price to be paid for greenhouse gas emissions reduction, and the terms in which it was couched proved highly accessible to the frames of reference of the various participants including sceptics. Along with the earlier invocation of a trust frame, the proposal was key to the construction of workable agreement. 
Now, an alternative reading of what happened might be that a workable compromise emerged merely as a result of group discussion moving from the science to politics and policy. Yet that is precisely what does not generally happen when it comes to climate change. In the deliberative forum conducted by Hobson and Niemeyer (2012), concrete policy discussion made no difference to the positions taken by sceptics, in the absence of the sorts of rhetorical moves we have highlighted. In addition, surveys show that even among those who accept the reality of anthropogenic climate change, there is deep dispute over policy measures - especially when it comes to anything that looks like a tax (Nisbet and Myers 2007, pp. 460-65). In Australia, where a large majority of people accepts the reality of climate change, the introduction of a carbon tax was a factor in the demise of the Labor government at the 2013 general election. Thus there is every reason to suppose that the simple fact of a shift from discussing science to discussing policy would actually amplify disagreement.

\section{Rhetorical bridges}

Invocation of the trust frame and Medicare levy analogy demonstrated a 'bridging' rhetorical effect inasmuch as it brought partisans of different positions to a point of consent to policies for mitigating climate change (on the concept of bridging rhetoric, see Dryzek 2010). Analogy is more conducive to bridging than metaphor, because (in rhetorical theory) a metaphor asserts that A is B - not just that A is like B in some respects. Metaphors can therefore be more confronting and disruptive than analogies. The effect we observed hinged on the perceived ability of a policy to address two critical considerations, namely, certainty about the use of public funds and policy impact and 
trust in institutions, of which partisans could make sense in their own terms. Participants came to realize that these requirements received equal recognition from others with whom they otherwise disagreed. As a result, they agreed to join each other in a collective problem solving process (even though that was not what the design of the forum required).

The prospective 'Medicare for the climate' invoked an established system which has gained public trust over the years and with which the participants had shared experience. By invoking the analogy, proponents of putting a price on the need to reduce emissions reached other participants with shared interest in trust, though they might still differ as to whom or what merited trust. Although the proposed levy might potentially provide assurance about transparency and dedication of the use of revenue, it might not guarantee any particular level of emissions reduction. The rhetorical analogy drew opponents of a carbon tax toward the more abstract shared commitment to certainty, while differences remained as to the interpretation of certainty, which for Kevin (the strong emissions trading supporter) meant guaranteed emissions reduction, rather than certainty about how revenues would be spent. The informal agreement around the acceptability of a levy emerged from a shared belief that these sorts of considerations could be recognized.

The main outcome of this process was acceptance of a willingness to mandate payment for greenhouse gas reduction, which managed to reach the domain of acceptability of those who had initially opposed a carbon tax, be they supporters of market-like measures or climate sceptics. These people began to see paying for climate change mitigation as a legitimate policy option, without necessarily preferring it in the sense of locating it as their first preference in a preference ordering. Kevin made the 
difference between individual preference and acceptance of a collective position abundantly clear: 'I'm against it [carbon tax] but I would say that the carbon tax would be the preferred option of us all'.

The sceptics Mike and Nancy still did not like the idea of pricing carbon, but they could accept it. Nancy continued to make a carbon tax the least preferred option after deliberation (see Lo 2013). Mike, in reflecting on his participation in the deliberative process considered himself part of an actionable agreement that was, however, far from a simple universal consensus. As he explained: 'Twenty randomly selected citizens representing a cross section of the electorate did arrive at a considered consensus. Well not quite, but close enough to form a probable electoral poll outcome.' His position (and that of Kevin just mentioned) here is consistent with invocation of a 'we-frame' (Dryzek and List 2003), which again might be something that can be produced by rhetoric. Still, Mike reiterated the fact that he could support a 'levy', and not exactly a 'tax'. Only the general policy framework through which the levy would be collected received his assent.

Epistemic dissensus on the part of the climate sceptics remained at the end of the process. Mike, after reading a news article about global warming a few days after the workshop, threatened to withdraw from his newly established accommodating stance: ' $I$ have almost returned to my original position of complete disregard for scientific evaluation after reading this rubbish article.' Thus he still questioned the validity of the science. At a normative level we observed no transformation in the group as a whole as a result of deliberation. Thus the real action was in terms of preferences, not values or epistemic judgments about climate science, made possible by the invocation of a trust frame and the subsequent 'Medicare for the climate' analogy. As we have indicated, these 
rhetorical moves meant that growing agreement on what to do did not have to depend on increased epistemic agreement (concerning climate science) and normative agreement, however illogical that might seem.

Now, it might be argued that the dynamics we observed were simply a result of climate change deniers having to engage differently-minded others in a civil setting - a situation very different to everyday life, where they (in common with most people) only talk to like-minded others. Social pressures might then lead to moderation. We can rule out this kind of explanation by contrasting our results with those of Hobson and Niemeyer (2012), who like us conducted a deliberative citizen forum on climate change in Australia containing sceptics. Hobson and Niemeyer found that their sceptics did not moderate their position in deliberation; two walked out, the others 'became more dogmatic and belligerent' in their exchanges with others (Hobson and Niemeyer 2012: 408). The key difference is that our forum featured an effective rhetorical bridge; theirs did not.

In our forum, the deniers were happy articulating their views, and did not change their position on the science at all. There was also no observable group pressure among participants for conforming to the majority preference that emerged toward the end of discussion, i.e. carbon tax or levy. Before the workshop, only three (out of eight) members of the most divided subgroup selected carbon tax as the first preference, suggesting tax advocates were initially not the majority. In fact, the formal discussion in this subgroup was led by Kevin and Mike, who were both against the carbon tax. If there was any normative pressure in this group it should have run against any tax option, but that proved not to be the case. 
Our claim is not that we can replicate what transpires in a small scale citizen forum in the larger public sphere, but rather that we can draw lessons from what we observe in that controlled setting to what kinds of processes and outcomes can be sought in the larger sphere. There is every reason to suppose rhetoric (for better or worse) is more available in that sphere, be it in informal conversations or large-audience oratory, than in citizen forums (Chambers 2009).

\section{Conclusion}

Rhetorical interventions involving framing and analogy in a deliberative process succeeded by drawing partisans of different positions - including, most notably, climate change deniers - into recognition that paying a price for the sake of climate change mitigation was acceptable. The 'Medicare levy for the climate' analogy in particular could only be specific to Australia - not only because it referred to a specific popular and trusted Australian tax, but also because its appeal was contingent upon the sceptics present being suspicious of the market, and so prepared to trust government - provided that its discretionary power is removed. In the United States, organized climate change denial is linked to right-wing politics hostile to government, and to a degree that happens in Australia too. But as we noted at the outset, the psychology of denial is complex, and we should not rush to an ideological reductionism that treats denial as an unreachable concomitant of a right-wing anti-government worldview. Rhetoric must always be context-specific: it works because the rhetorician knows something (or, in our case, stumbles across something) about the particular dispositions of the audience. 
One limitation of our results might seem to stem from the fact that we were looking at a small-scale forum, not the larger public sphere. Many treatments of rhetoric (e.g., Chambers 2009) see it as something exercised by a leader addressing a very large audience. Traditionally that would have involved oratory, though written communication is also possible. However, most students of rhetoric see it as pervasive in all communication, in one-on-one talk as much as large-audience oratory. Moreover, we are confident that the small-scale forum, whose dynamics are so much easier to study than those of a broader public, does tell us something about what can be sought in the larger public sphere. Small-group deliberations, because they are overseen by facilitators who guide participants to respectful listening and the crafting of arguments, are often seen as unpromising sites for rhetoric. So if rhetoric can take effect in such a relatively rationalistic setting, it ought to take effect still more readily in the more informal public sphere.

The particular kind of rhetoric that should be sought is 'bridging' in character, in that it can reach those who do not share the speaker's perspective. 'Bonding' rhetoric, appealing only to one's own side, is likely only to entrench division (the limits of a climate change communicator such as $\mathrm{Al}$ Gore can be understood in this light). Bridging rhetoric can be in short supply in adversarial political systems such as Australia, which may be one reason why such systems (including also the United States and Canada) have had more trouble in processing environmental issues in general and climate change in particular than more consensual democracies (such as those found in northern Europe). But that is precisely why effective rhetoric is so much more necessary in adversarial systems than in consensual ones. Historically, great rhetoricians such as Martin Luther 
King, Jr. and Nelson Mandela are known for their effective bridging rhetoric in situations of deep division - not in situations of consensus. In this light, what we need is not just Medicare for the Climate - but Mandela (or multiple Mandelas) for the climate. 


\section{References}

Chambers, S., 2009. Rhetoric and the public sphere: Has deliberative democracy abandoned mass democracy? Political Theory, 37 (3), 323-350.

Corner, A., Whitmarsh, L. and Xenias, D., 2012. Uncertainty, scepticism and attitudes towards climate change: Biased assimilation and attitude polarisation. Climatic Change, 114 (3-4), 463-478.

Dryzek, J.S., 2010. Rhetoric in democracy: A systemic appreciation. Political Theory, 38 (3), 319-339.

Dryzek, J.S. and List, C. 2003. Social choice theory and deliberative democracy: A reconciliation. British Journal of Political Science, 33, 1-28.

Dryzek, J.S. and Niemeyer, S., 2006. Reconciling pluralism and consensus as political ideals. American Journal of Political Science, 50 (3), 634-649.

Dunlap, R. and McCright, A.M., 2008. A widening gap: Republican and Democratic views on climate change. Environment, 50, 26-35.

Higgins, R.C.A. 2008. "The Empty Eloquence of Fools": Rhetoric in Classical Greece. In Gleeson, J.T. and Higgins, R.C.A., eds., Rediscovering Rhetoric: Law, Language and the Practice of Persuasion. Annandale, NSW: Federation Press, pp. 3-44.

Hobson, K. and Niemeyer, S. 2012. "What Sceptics Believe": The Effects of Information and Deliberation on Climate Change Scepticism. Public Understanding of Science 22 (4): 396-412.

Hulme, M., 2009. Why we disagree about climate change Cambridge: Cambridge University Press. 
Kahan, D.M., Peters, E., Wittlin, M., Slovic, P., Ouellette, L.L., Braman, D., and Mendel, G. 2012. The Polarizing Impact of Science Literacy and Numeracy on Perceived Climate Change Risks. Nature Climate Change 2: 732-5.

Kuypers, J.A. 2009. Framing Analysis. In Kuyper, J.A., ed., Rhetorical Criticism: Perspectives in Action. Lanham, MD: Lexington Books, pp. 181-204.

Lo, A.Y., 2013. Agreeing to pay under value disagreement: Reconceptualizing preference transformation in terms of pluralism with evidence from small-group deliberations on climate change. Ecological Economics, 87, 84-94.

Lo, A.Y., 2014. The right to doubt: climate-change scepticism and asserted rights to private property. Environmental Politics, 23 (4); pages 549-569. http://dx.doi.org/10.1080/09644016.09642014.09884310.

Lomborg, B. 2010. Introduction. In Lomborg, B. ed. Smart solutions to climate change : Comparing costs and benefits Cambridge: Cambridge University Press.

McCright, A. and Dunlap, R. (2011) Cool dudes: the denial of climate change among conservative white makes in the United States. Global Environmental Change 21, (4):1163-1172.

Moser, S.C. \& Dilling, L. 2011. Communicating climate change: Closing the scienceaction gap In Dryzek, J.S., Norgaard, R.B. \& Schlosberg, D. eds. The Oxford Handbook of Climate Change and Society. Oxford: Oxford University Press.

Norgaard, K.M. 2011. Living in Denial: Climate Change, Emotions and Everyday Life. Cambridge, MA: MIT Press. 
Nisbet, M.C. \& Myers, T. 2007. Twenty years of public opinion about global warming. Public Opinion Quarterly 71 (3): 444-70.

Poortinga, W., Spence, A., Whitmarsh, L., Capstick, S. \& Pidgeon, N.F., 2011. Uncertain climate: An investigation into public scepticism about anthropogenic climate change. Global Environmental Change, 21 (3), 1015-1024.

Washington, H. \& Cook, J. 2011. Climate Change Denial: Heads in the Sand. London: Earthscan.

Whitmarsh, L., 2011. Scepticism and uncertainty about climate change: Dimensions, determinants and change over time. Global Environmental Change, 21 (2), 690700. 